Sharif University of Technology
Scientia Iranica
Transactions E: Industrial Engineering
hCIENTIA

\title{
A combined benders decomposition and Lagrangian relaxation algorithm for optimizing a multi-product, multi-level omni-channel distribution system
}

\author{
A. Hendalianpour ${ }^{\mathrm{a}, *}$, M. Fakhrabadi ${ }^{\mathrm{b}}$, M.S. Sangari ${ }^{\mathrm{c}}$, and J. Razmi ${ }^{\mathrm{a}}$ \\ a. School of Industrial Engineering, College of Engineering, University of Tehran, Tehran, Iran. \\ b. Department of Business and Management Science, Norwegian School of Economics, Bergen, Norway. \\ c. Department of Industrial and Systems Engineering, Fouman Faculty of Engineering, College of Engineering, University of \\ Tehran, Iran.
}

Received 3 June 2019; received in revised form 16 January 2020; accepted 9 April 2020

\author{
KEYWORDS \\ Omni-channel; \\ Distribution network; \\ Mathematical \\ modeling; \\ Benders \\ decomposition; \\ Lagrangian relaxation.
}

\begin{abstract}
The development of supply chain distribution systems from single- to multichannel networks for delivering items to end customers has effected many changes in the retail sector. Following the adoption of multi-channel distribution strategies and rapid development of relevant technologies, the omni-channel approach can yield significant benefits and facilitate trade with customers. This paper aims to optimize a multi-product, multi-level omni-channel distribution network and shipping flows of products within the network under uncertain conditions. A multi-objective mathematical model is developed that minimizes the costs of supply chain while maximizing customer satisfaction over different scenarios. In order to solve the proposed model, a combined algorithm is developed based on Benders Decomposition (BD) and Lagrangian Relaxation (LR). The presented model and solution approach are implemented in the case study of a distribution system, a large e-commerce startup, and an online store. Five different scenarios with different service levels are investigated and the numerical results are discussed compared to previous findings. The efficiency of the proposed combined BD-LR solution algorithm is also demonstrated. The results obtained from the case study show that higher service levels are correlated with the higher levels of customer satisfaction and lower costs of the system.
\end{abstract}

(C) 2022 Sharif University of Technology. All rights reserved.

\section{Introduction}

In today's business environment, gaining advantage in competition with other supply chains is dependent on several requirements, such as reducing cost, increasing service level, and enhancing the quality of products $[1,2]$, which lead to higher customer satis-

*. Corresponding author.

E-mail addresses: hendalianpour@ut.ac.ir (A.

Hendalianpour); mahnaz.fakhrabadi@nhh.no ( $M$.

Fakhrabadi); mssangari@ut.ac.ir (M.S. Sangari);

jrazmi@ut.ac.ir (J.Razmi)

doi: $10.24200 /$ sci. 2020.53644 .3349 faction levels as the most significant factor affecting business success [3]. Supply chains are faced with high dynamism and uncertainty in the business environment [4], which is more vivid when demand and order of the end customers are concerned [5]. The supply chain network should be able to deal with uncertain demand of all of its elements including producers, suppliers, and distribution centers [6].

Traditionally, a supply chain is characterized by distribution flows of materials and information between supply chain members [7]. Distribution of items in supply chain, defined as transportation of products from supplier to customer, is the key driver of a company's profit because it directly affects supply chain costs, 
customer experience, and customer loyalty $[8,9]$. In addition, the retail industry has drastically changed in recent years. The traditional trade has evolved from a set of activities in one channel into continuous activities in multiple channels with similar information [10]. Now, modern customers shop online using their cellphones and laptops or through their social networks $[11,12]$. The new communication channels define new factors affecting sales and customer's decisions [13].

Nowadays, many business owners use multichannel methods and consumers' experiences for optimization. However, a multi-channel approach cannot access the modern sellers' expected information, speed, and personal experiences [14,15]. In addition, significant diversity of different channels in terms of information of product, price, consumer experience, and the level of services is possible [16].

Introduction of the Internet to the business world has offered new communication channels for facilitating shopping, making selling products by producers, and purchasing products by customers faster and more precise [17]. Moreover, purchasing by computers, cellphones, and various applications along with traditional purchasing methods such as buying from stores or selecting the intended items from catalogues have covered all social strata, tastes, and habits [18]. This method of using all available means, called omnichannel, enables organizations to take greater control over pricing and selection of products and to receive proper feedback from market and customers helping them in production and pricing decisions [19].

In today's chaotic business world, a company that can use all communication channels to satisfy customers' demands and wishes in a short period of time and at any time and place will be successful [20]. With the new purchasing methods, customers can purchase 24 hours, seven days a week [21]. In this method, customers can search for and order product at any place and through any means (i.e., visiting physical store, the Internet, laptop, and iPhone) [22]. Then, the product will be delivered to customer's intended location such as stores and other predetermined locations for delivery of product (i.e., third-party locations). In addition, return of damaged or problematic items can be done through ways similar to reception of items [23].

Among the advantages of omni-channel, one could point to increased customer satisfaction, increased sales, enhancement of market share, higher profit margin, more effective brand advertisement, new income flows, better collection of customer and market data, increased efficiency, and creation of new job opportunities [24]. The omni-channel approach is still at the beginning of the road. In particular, the theoretical knowledge on how to develop practical frameworks to evaluate and select appropriate channels through exploration of all the ways in an omni-channel system is lacking. Previous studies on the omni-channel systems have mostly adopted a descriptive approach instead of planning and decision-oriented approaches [25,26], which open a route to greater enhancement in this modern and appealing area of purchasing that facilitates buying and attracts numerous people. Having read various journal papers on omni-channel approach and its significance and efficiency in the distribution system as well as noticing a gap in the literature, the researchers have become motivated to conduct a study on how to optimize a multi-product, multi-level omnichannel distribution system through mathematical programing rather than a descriptive approach. Hence, the purpose of this paper is to develop a model to enhance the efficiency of a distribution system using the omni-channel approach while reducing costs and increasing customer satisfaction. The findings of this study can have many contributions to the distribution system in both Iran and the whole distribution systems of the world. The reason is that this research can incorporate available ways and parts of sales-tocustomer sales, customer-to-customer, wholesaler-tocustomer, and middle-warehouse in modeling for the decision-making purpose. Therefore, it can test a wide variety of possible scenarios and offer the best solutions and techniques for increasing customers' satisfaction level and minimize the costs of delivery.

The remainder of this paper is organized as follows. Section 2 reviews the relevant studies on the distribution systems. Section 3 presents the problem statement. Section 4 formulates the mathematical model developed for the presented problem. Section 5 describes the proposed solution approach. Finally, Section 6 concludes the paper with a summary of findings and some directions for future research.

\section{Literature review}

In the past decade, the retail world witnessed many changes. The emergence of online channels (e.g., mobile channels and social networks) has changed the retail model, its implementation, and sellers' behavior and expectations. While multi-channels were popular in the past decade, modification of omni-channel has recently turned into a requirement [27].

There are few papers on optimization of omnichannel distribution systems including Sharma et al. [13] who suggested that an optimal design of distribution networks requires paying attention to specifications of products and considering the cost and service level as the most important decisionmaking criteria. They used Multiple Criteria Decision Analysis (MCDA) for designing a distribution network by taking both quantitative and qualitative factors concurrently [28]. Chan and Kumar [6] introduced multiple Ant Colony Optimization (ACO) algorithm 
to design a distribution network within a supply chain. Their proposed model intends to minimize the transfer time and degree of imbalance between distribution centers. Cintron et al. [16] employed multi-criteria mixed-integer Linear Programming (LP) for designing a distribution network of supply chain. In their research, optimal configuration of plant, producers, and consumers in a distribution network were deemed as noteworthy influential factors.

Using the graphic evaluation and revision technique, $\mathrm{Li}$ and Liu [29] introduced a simple and integrated random mathematical method for further analysis of distribution in a supply chain. With regard to illustrating the variation of ordering time and inventory, they conducted sensitivity analysis to modify the demand rate and order quality of end customers. In another study, Ashayeri et al. [30] developed an impenetrable mixed integer-programming model for the problem of distribution network design with a third-party logistics service provider. The objective was to minimize the operational cost of the whole distribution network.

Pop et al. [31] presented a reverse distribution system to design a sustainable distribution network. They applied the nearest neighbor method as well as an innovative method premised on capacity of distribution centers and demand for supply. Ahmadi-Javid and Hoseinpour [32] developed a location-inventory-pricing model for further design of distribution network of a supply chain. The model was characterized by pricesensitive demand and constrained inventory capacity where the objective was to increase total profit. The authors proposed a Lagrangian Relaxation (LR) algorithm for solving the model.

Hübner et al. [33] conducted market studies and interviewed a set of major omni-channel retailers to provide information on factors affecting logistics services, costs of omni-channel retailing, the current structure and processes of omni-channel distribution and the ways that such structures and processes can be systematized, and the basic requirements for their applications.

Huré et al. [34] identified the key characteristics of omni-channel notion and designed a mixed qualitativequantitative model for evaluation of purchasing value through omni-channel distribution method. Hosseini et al. [25] proposed an economic decision-making model to compare omni-channel strategies in terms of their contribution to long-term value creation for the organization, while taking into account offline and online channels, open and closed channels, non-consecutive trips by customers, and performance of the customer channels.

Abdulkader et al. [21] introduced a vehicle routing problem in which groups of retail stores are responded by a distribution center and a fleet of vehicles based on omni-channel concept. Their mentioned problem is a generalization of picking up and delivery problem and capacitated vehicle routing problem. The paper introduced a mathematical formulation to define this problem and presented two solution approaches: twophase heuristic and multi-ant colony algorithm. We are going to compare our results with the work results of Abdulkader et al. [21].

Recently, Kang [35] worked on interrelationships among social-local-mobile consumers' fashion lifestyle, perceptions of the showrooming and webrooming value and omni-channel shopping intention, and intention of product review sharing as a post-purchase behavior using structural equations. In addition, Ryu et al. [36] categorized firms into two groups: those that only use online channel and those that use both online and offline channels (omni-channel) to sell their products, and the efficiencies of the two groups are compared using meta-frontier analysis.

The review of distribution methods and their development trend over the past few years signifies the superiority of the omni-channel distribution strategy wherein modern distribution tools and technologies are used. In spite of the need for developing omni-channel strategies and implementing optimal distribution plans that better satisfy requirements of customers in today's life style, almost all previous research in this field is focused on descriptive aspects. The literature review indicates that there are few studies on planning modern omni-channel distribution and retailing. In particular, research on optimization and decision-making in the omni-channel retailing context is in its infancy. In addition, despite variations and uncertainties inherent in the distribution networks, they have been mostly investigated under deterministic conditions. This reduces the accuracy and applicability of the findings of previous studies. This study aims to design a multiobjective mathematical model to optimize an omnichannel distribution system. In order to further comply with the real-world situations, the proposed model incorporates uncertainty in demand as well as distribution and retail network. The paper's contributions are summarized as follows:

- Taking into account the practical approach by introducing a case study with the potential of different distribution systems in order to cover all aspects of omni-channel;

- Considering uncertainty in demand, distribution, and retail network;

- Presenting two objective functions for minimizing the costs of distribution chain and increasing customer satisfaction;

- Using combined Benders Decomposition (BD) and LR to solve the problem. 


\section{Problem description}

The increasing use of the Internet and application development was followed by a significant global growth in online sales. This is witnessed by increased sales in online channels [33]. The process of retail digitalization has significantly influenced the distribution and retailing echelons in supply chains and changed the structure of the retail market. Although online business is continually developing and mobile devices are going to play a more important role in the business, physical stores are still the key retail spaces $[33,37]$. The customers having access to digital tools have more information and ability to purchase. This process describes an omni-channel buyer. Such a buyer always uses communication devices, such as mobile or laptop, to connect to the Internet. In doing so, the buyer is informed of the changes in the market and the new products so that he/she gets the best deal and receives the purchased items at the intended time and place.

The omni-channel approach is a logical step of evolution from the multi-channel approach as it consists of all purchasing methods. In this approach, consumers' experience of each channel is identical and switching from one channel to another does not lead to reception of new or different information. The coordination of information input makes the omnichannel approach more complicated than the traditional multi-channel approach. The term "omni" implies that customers can buy through every channel, as information of purchasing process is available in all of the channels in real time.

Based on the above explanations, the problem addressed in this paper is to design an efficient distribution optimization model by taking the economic indices and profitability of the whole omni-channel participatory retail distribution chain. The simultaneous reduction of total costs and increase of profitability while taking into account service level as a measure of customer satisfaction are sought under uncertain conditions and based on different scenarios. Since the problem is NP-hard, a heuristic solution approach is proposed based on a combination of BD and LR methods, which is a strong contributing point of this work. Our paper attempts to develop a model to enhance the efficiency of a distribution system considering the omnichannel approach. The mathematical model pursues some goals including reducing costs and increasing customer satisfaction, which can be named as the bases of a supply chain. Use of BD and LR methods to optimize mathematical model is one difference between this paper and the Abdulkader approaches, as it is shown that this method generates better and more reliable results by considering uncertainties. In fact, LR method creates an appropriate upper and lower bound for $\mathrm{BD}$ to reach convergence in a proper time.
Introduction of two objective functions in terms of minimizing all costs and maximizing customer satisfaction and solving of the problem by a hybrid of BD and LR represent the innovations of this paper in comparison with Abdulkader et al. [21], with one objective function as minimizing just distribution cost and employing Ant-colony and Multi-heuristic methods to solve the mathematical model. Runtime evolution is the first priority, which is seen by using composition of LR, and $\mathrm{BD}$, which has also been mentioned in some works [3840].

\section{Mathematical modeling}

In this study, modeling is based on flow of items in retail distribution chain. The modeling of retail distribution chain is a zero-one Mixed Integer Programming (MIP) in which the objective function intends to minimize the costs of distribution chain and increase customer satisfaction. Two ways for sales of items through the distribution system are taken into account: physically visiting the store and online sales. According to Figure 1, the model incorporates multiple distribution channels. It comprises direct sales of items through online sale system and delivery to the customer's location and shipping via intermediate warehouses or distribution centers, which are closest to the customers. The second method is through purchasing centers within the distribution network. The third method functions based on purchasing from intermediate warehouses and delivery to customer's location. Therefore, the shipping routes from the distribution center to the customers can be summarized as follows:

- Direct shipping from distribution center to the customer;

- Shipping from distribution center to convenience store where customers can go and choose the item;

- Shipping from distribution center to the intermediate depot, from intermediate depot to the convenience store where the customer can go and choose the item;

- Shipping from distribution center to the intermediate depot, from intermediate depot to the retail store which allows the customer to go and pick up the item;

- Shipping from distribution center to a retail store which allows the customer to go and pick up the item;

- Shipping from distribution center to an automated package station that customer can go to and pick up the item; 


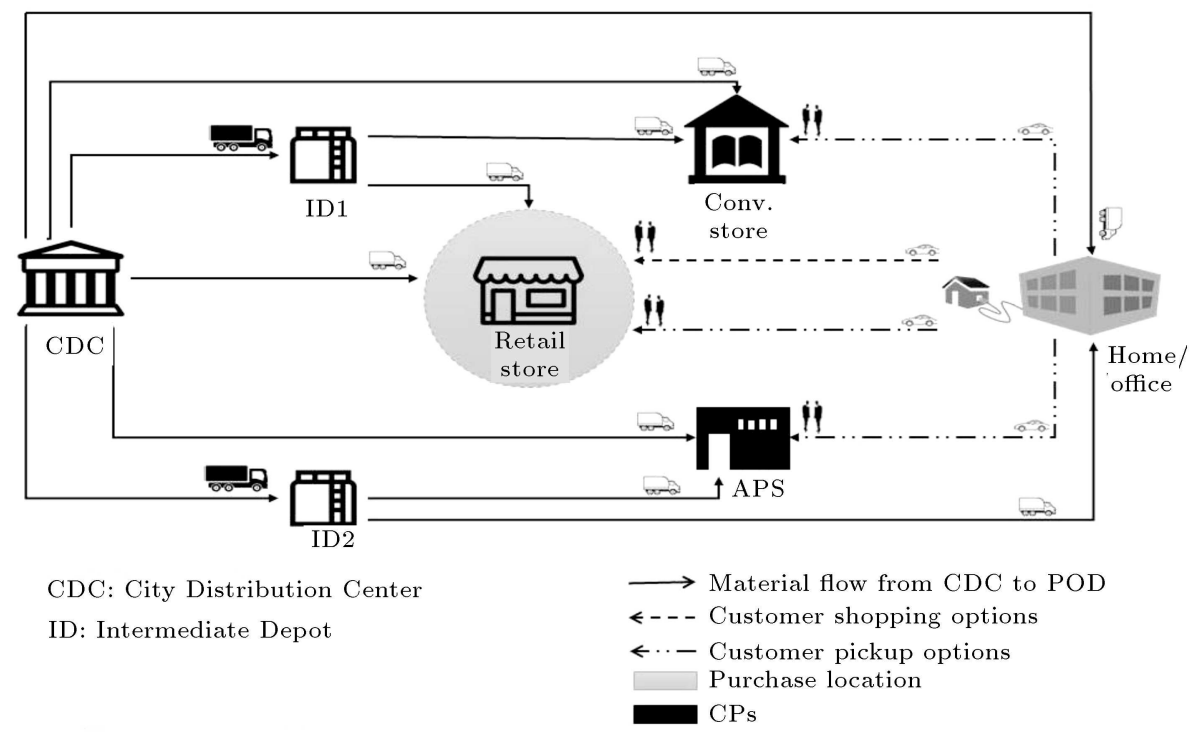

Figure 1. The structure of an omni-channel distribution system.

- Shipping from distribution center to an intermediate depot and, then, to an automated package station that the customer can go to and pick up the item;

- Shipping from distribution center to an intermediate warehouse and, then, to the customer.

Considering the fact that in the company/case, the close-to-buyer distribution centers as well as predetermined centers are similar to the intermediate warehouses and shipping of items from starting point (i.e., distribution center) can be done in two general ways:

- Shipping from the distribution center to the customer;

- Shipping from the distribution center to the intermediate warehouse and, then, to the customer.

Only one of the two methods detailed above should be adopted. In addition, the following assumptions are made to reduce the distribution costs:

- The same vehicle, which ships an item from the distribution center to the intermediate warehouse, will ship the item from there to the customer;

- If the customer opts for the second method of receiving his order (i.e., via intermediate warehouse), the vehicle should go to the intermediate warehouse and, then, visit the customer.

Other assumptions made in the proposed model are as follows:

- A multi-product, multi-retailer system with multiple distribution channels is taken into account;

- At each distribution center, a fixed cost is incurred for placing each order and a cost is incurred for holding the inventory;
- The intermediary warehouse established to satisfy the consumers' demand must be visited before the end customers and by the same vehicle;

- A homogeneous fleet type is assumed and the vehicles have the same capacities;

- The linear and stochastic demand is assumed.

The following notations are used in developing the mathematical model.

\section{Sets and indices}

$I \quad$ Set of the city distribution centers $i \in I$

$K \quad$ Set of intermediary depots $k \in K$

$j \quad$ Set of delivery points $j \in J$

$M \quad$ Set of distributable items (i.e., sellable products) $m \in M$

$S \quad$ Set of scenarios $s \in S$

$V \quad$ Set of vehicles $v \in V$

\section{Parameters}

$P_{i m}^{s} \quad$ Usable capacity of distribution center $i$

$\begin{array}{ll} & \text { in scenario } s \\ C I D_{k m}^{s} & \text { Usable capacity of intermediary depot }\end{array}$ $k$ in scenario $s$

$D_{m}^{s} \quad$ Demand for item $m$ in scenario $s$

$\operatorname{Re}_{k m}^{s} \quad$ The number of items $m$ rejected to intermediary $k$ in scenario $s$

$C_{i k m}^{s} \quad$ Cost of shipping item $m$ from distribution center $i$ to intermediary depot $k$ in scenario $s$

$C_{j k m}^{s} \quad$ Cost of shipping item $m$ from intermediary depot $k$ to delivery point $j$ in scenario $s$ 


\begin{tabular}{|c|c|}
\hline$C_{i j m}^{s}$ & $\begin{array}{l}\text { Cost of shipping item } m \text { from } \\
\text { distribution } i \text { to delivery point } j \text { in } \\
\text { scenario } s\end{array}$ \\
\hline$f_{k}^{s}$ & $\begin{array}{l}\text { Fixed cost of establishing intermediary } \\
\text { depot } k \text { in scenario } s\end{array}$ \\
\hline$D C_{i}^{s}$ & $\begin{array}{l}\text { Fixed cost of establishing distribution } \\
\text { center } i \text { in scenario } s\end{array}$ \\
\hline$v_{k m}^{s}$ & $\begin{array}{l}\text { Holding cost of item } m \text { in intermediary } \\
\text { depot } k \text { in scenario } s\end{array}$ \\
\hline$B_{\min }$ & $\begin{array}{l}\text { Minimum number of distribution } \\
\text { centers that can be established in } \\
\text { scenario } s\end{array}$ \\
\hline$B_{\max }$ & $\begin{array}{l}\text { Maximum number of distribution } \\
\text { centers that can be established in } \\
\text { scenario } s\end{array}$ \\
\hline$L O S_{i j m}^{s}$ & $\begin{array}{l}\text { Service level of shipping item } m \text { from } \\
\text { distribution center } i \text { to delivery point } j \\
\text { in scenario } s\end{array}$ \\
\hline$a^{s}$ & Probability of scenario occurrence $s$ \\
\hline $\operatorname{cap}_{i j m}^{s}$ & $\begin{array}{l}\text { Shipping capacity percentage of item } \\
m \text { from distribution center } i \text { to delivery } \\
\text { point } j \text { in scenario } s\end{array}$ \\
\hline$M^{s}$ & A large number for scenario $s$ \\
\hline$S_{i j}^{v}$ & $\begin{array}{l}\text { Time required for vehicle } v \text { to travel } \\
\text { from distribution center } i \text { to delivery } \\
\text { point } j\end{array}$ \\
\hline$S_{i k}^{v}$ & $\begin{array}{l}\text { Time required for vehicle } v \text { to } \\
\text { travel from distribution center } i \text { to } \\
\text { intermediary depot } k\end{array}$ \\
\hline$S_{k j}^{v}$ & $\begin{array}{l}\text { Time required for vehicle } v \text { to travel } \\
\text { from intermediary depot } k \text { to delivery } \\
\text { point } j\end{array}$ \\
\hline$T_{k}^{v}$ & $\begin{array}{l}\text { Time required for loading/unloading of } \\
\text { vehicle } v \text { in intermediary depot } k\end{array}$ \\
\hline$C_{k m}^{s}$ & The cost of rejected item $m$ \\
\hline
\end{tabular}

\section{Decision variables}

$x_{i j m}^{s} \quad$ Shipping flow of item $m$ from distribution center $i$ to delivery point $j$ in scenario $s$

$x_{k j m}^{s} \quad$ Shipping flow of item $m$ from intermediary depot $k$ to delivery points $j$ in scenario $s$

$x_{i k m}^{s} \quad$ Shipping flow of item $m$ from distribution center $i$ to intermediary depot $k$ in scenario $s$

$y_{k}^{s} \quad$ A zero-one variable showing whether intermediary depot $k$ is established in scenario $s$

$y_{i}^{s} \quad$ A zero-one variable showing whether distribution $i$ is established in scenario $s$
$y_{i j} \quad$ A zero-one variable showing whether the items are shipped from distributor $i$ to delivery point $j$
$y_{i k}^{\nu} \quad$ A zero-one variable showing whether the items are shipped from distributor $i$ to intermediate depot $k$ with vehicle $v$
$y_{k j}^{\nu} \quad$ A zero-one variable showing whether the items are shipped from intermediate depot $k$ to delivery point $j$ with vehicle $v$

\section{Objective functions}

$$
\begin{aligned}
\min F_{1}= & \sum_{k} \sum_{s} f_{k}^{s} \cdot y_{k}^{s}+\sum_{t} \sum_{s} D_{i}^{s} \cdot y_{i}^{s} \\
& +\sum_{i} \sum_{k} \sum_{m} \sum_{s} C_{i k m}^{s} \cdot x_{i k m}^{s} \\
& +\sum_{i} \sum_{j} \sum_{m} \sum_{s} C_{i j m}^{s} \cdot x_{i j m}^{s} \\
& +\sum_{j} \sum_{k} \sum_{m} \sum_{s} C_{k j m}^{s} \cdot x_{k j m}^{s} \\
& +\sum_{k} \sum_{m} \sum_{s} C_{k m}^{s} \cdot \operatorname{Re}_{k m}^{s} .
\end{aligned}
$$

The first objective function is of minimization type and aims to minimize costs. The first and second parts in objective function (1) denote the costs of establishing intermediary depots and distribution centers. The following parts in objective function (1) comprise the cost of delivery from distribution center to intermediary depot, from distribution center to delivery depot, and from intermediary depot to delivery point. The last part is the cost of holding items in the intermediary depots. This function aims to minimize all costs of process.

$$
\begin{aligned}
\max F_{2}= & \sum_{m} \sum_{s} a^{s} \cdot D_{m}^{s}\left[\sum_{i} \sum_{j} \sum_{m} \sum_{s} L o s_{i j m}^{s} \cdot D_{m}^{s}\right. \\
& \left.-\sum_{i} \sum_{j} \sum_{m} \sum_{s}\left(1-\operatorname{Cap}_{i j m}^{s}\right) \cdot D_{m}^{s}\right]
\end{aligned}
$$

The objective function (2) deals with maximizing customer satisfaction over all scenarios. It maximizes the level of customer satisfaction based on the increase in the service level in view of the probability of occurrence of each scenario as well as the service level defined for each transmission path. The greater transmission capacity results in higher service level and therefore, higher customer satisfaction. 


\section{Constraints}

$$
\begin{aligned}
& \sum_{j} x_{i j m}^{s} \leq P_{i m}^{s} \\
& \forall i, m, s, \quad(3) \\
& \sum_{j} \sum_{m} x_{k j m}^{s} \leq C I D_{k}^{s} \\
& \forall s, k, \\
& \sum_{i} \sum_{j} x_{i j m}^{s} \geq D_{m}^{s} \\
& \forall m, s, \quad(5 \\
& \sum_{i} \sum_{k} x_{k j m}^{s} \geq D_{m}^{s} \\
& \forall m, s, \\
& \sum_{i} \sum_{j} \sum_{m} x_{i j m}^{s}-M^{s} \cdot y_{k}^{s} \leq 0 \quad \forall s, \quad \forall k \in I, \\
& \sum_{k} \sum_{j} \sum_{m} x_{k j m}^{s}-M^{s} \cdot y_{k}^{s} \leq 0 \quad \forall s, \quad \forall k \in I, \\
& \sum_{i} \sum_{j} \sum_{m} x_{i j m}^{s}-\sum_{k} \sum_{j} \sum_{m} x_{k j m}^{s}=0 \quad \forall s, \\
& \sum_{k} y_{k}^{s} \geq B_{\min } \quad \forall s, \\
& \sum_{k} y_{k}^{s} \leq B_{\max } \\
& \sum_{i} \sum_{k} y_{i k}^{\nu}-\sum_{k} \sum_{j} y_{k j}^{\nu}=0 \\
& S_{i j}^{\nu} \geq y_{k j}^{\nu}\left(S_{i k}^{\nu} \cdot y_{i k}^{\nu}+S_{k j}^{\nu} \cdot y_{k j}^{\nu}+T_{k}^{\nu}\right) \quad \forall \nu, \\
& \sum_{i} \sum_{m} x_{i k m}^{s} \leq C I D_{k}^{s} \\
& \forall k, s, \\
& y_{k}^{s}, y_{i k}^{\nu}, y_{k j}^{\nu}, y_{i j} \in\{0,1\} \text {, } \\
& x_{i j m}^{s}, x_{i k m}^{s}, x_{k j m}^{s} \geq 0 . \\
& \forall s, \\
& \forall \nu,
\end{aligned}
$$

Constraints (3) and (4) guarantee that the shipping flow of an item from distribution center $i$ to delivery point $j$ and from intermediary depot $k$ to delivery point $j$ is not less than available capacity in the distribution center, respectively. Constraints (5) and (6) ensure that the overall shipping flow of an item from distribution centers and intermediary depots to delivery point $j$ satisfy the item's demand. Constraints (7) and (8) guarantee that the shipping flows from distribution center $i$ to delivery point $j$ and from intermediary depot $k$ to delivery point $j$ (where an intermediary deport is already there) are non-negative.

Constraint (9) suggests that the product of deduction of all of the flow of shipping item from distribution center $i$ to intermediary depot $k$ as well as flow of shipping item from intermediary depot $k$ to delivery point $j$ should be equal to zero. In other words, all incoming and outgoing shipping flows of intermediary deport should be equal and no item is stored in intermediate depots to decrease costs. Constraints (10) and (11) show the minimum and maximum number of intermediary depots, respectively, which can be established in each scenario. Constraint (12) guarantees that the same vehicle shipping a customer's intended item from distribution center to depot point ships the item from there to the customer. Constraint (13) implies that where an item is shipped from depot point to the customer, the vehicle should first visit the depot and, then, travel from there to the customer's delivery point. Constraint (14) guarantees that the shipping flow of an item from distribution center $i$ to intermediary depot $k$ does not exceed the capacity of intermediary depot. Constraint (15) shows that the variables corresponding to the establishment of intermediary depots as well as the paths from distribution centers to delivery points and intermediary depots and the paths from intermediary depots to delivery points are all of zeroone type. Constraint (16) ensures the non-negativity of shipping flows and shipping times from distribution centers to delivery points and intermediary depots as well as from intermediary depots to delivery points.

\section{Proposed solution approach}

In order to solve the mathematical model presented in the previous section, a heuristic approach is developed. The proposed solution approach is based on the combination of $\mathrm{BD}$ and $\mathrm{LR}$. The $\mathrm{BD}$ algorithm is limited to convex optimization problems and the LR algorithm can overcome this limitation. In this way, the bounds of $\mathrm{BD}$ are developed and the calculation time is reduced, while $\mathrm{BD}$ helps the problem to converge at finite iterations, as well. The BD divides the original model into the main problem and a sub-problem and the LR creates acceptable approximate solutions to the main problem by relaxing all constraints and providing some information on the optimal solution of the main problem. Such a combined BD-LR approach represents an efficient method to solve mathematical model and achieve a satisfactory optimal solution. In this section, the proposed combined BD-LR solution approach is described to decompose our model into two sub-problems, which can be solved by well-known solution algorithms.

\subsection{Benders Decomposition (BD)}

BD method is based on the decomposition of MIP model to the main problem and a sub-problem, which are solved using one another's solute ion. The subproblem includes the state variables and related constraints, while the main problem includes the integer 
variables and one state variable that relates the two problems together. An efficient solution to the main problem provides a lower bound for the objective function Rebennack [41]. Using the solution obtained from the main problem, one dual model is solved for the sub-problem by fixing the integer variables as the input data. Based on this solution, we can define an upper bound for the whole objective of the problem. In addition, the dual solution to the sub-problem is used for the development of the Benders' cut that includes the state variables added to the main problem. In the subsequent repetition, this cut is added to the main problem and by using the solution to this problem, a new lower bound is obtained for the overall problem, which is guaranteed not to be worse than the current lower bound. In this way, the main problem and the sub-problem are solved until the stopping condition is met, i.e., the upper and lower bounds get less than a threshold value [42]. The BD algorithm can provide an efficient solution within a limited number of repetitions. Herein, this algorithm is reviewed and the $t$-stage problem is solved (Eqs. (17) and (18)):

$$
\begin{array}{ll}
\text { (M) } & M\left(x_{1}\right):=\max _{x_{t+1}, y_{t} \geq 0} \sum_{t=1}^{T} f_{t}\left(x_{t+1}, y_{t}\right), \\
\text { s.t.: } & h_{t}\left(x_{t}\right)-g_{1},\left(x_{t+1}, y_{t}\right) \leq 0, \\
& g_{2},\left(x_{t+1}, y_{t}\right) \leq 0 .
\end{array}
$$

In this equation $(M), x_{t}=x_{t+1}^{1}+x_{t}^{2}$ shows the number of the decision variables and constrains for stage $t$ and $-t$ is the vector of the variable with Constraint (16). In $(M)$, we assume that there is a solution fitting Constraints (16) and (17). Therefore, the region of $M$ is full. $M$ is good for Linear Programming (LP) and Mixed Integer Linear Programming (MILP) as well as non-linear and mixed-integer programming models. We use this structure to make a decomposition technique based on the Nested Benders Decomposition (NBD). By the decompositions, we have a recursive formula. $M$ in the recursive form is as follows:

$$
\begin{aligned}
& \left(M_{t}\right) \eta\left(x_{1}\right)=\max _{x_{t+1}, y_{t} \geq 0} f_{t}\left(x_{t+1}, y_{t}\right)+\eta_{t+1}\left(x_{t+1}\right), \\
& \text { s.t.: } \quad f_{t}\left(x_{t}\right)-g_{1},\left(x_{t+1},+y_{t}\right) \leq 0 \\
& g_{2},\left(x_{t+1}, y_{t}\right) \leq 0 .
\end{aligned}
$$

The limitation is that the objective function should be concave, while linear Benders cuts should be optimality used in the decompositions. The LR can overcome this limitation.

\subsection{Lagrangian Relaxation (LR)}

The LR is used as an efficient approach to solving MIP models. While various innovative solution algorithms are employed to solve mathematical models, a major problem is that we do not know how good our solution will be. In many cases, the solution obtained from such algorithms may be either completely efficient or nearly efficient; however, in other cases, it may not be considered as an efficient solution. The LR algorithm cab is briefly described in the following. For $\lambda_{1}, \cdots, \lambda_{T}$, the LR of the model $M$ is formulated as follows:

$$
\begin{gathered}
\left(L_{\lambda}\right) L\left(\lambda_{1}, \cdots, \lambda_{t}, x_{1}\right):=\sup _{x_{t+1}, y_{t}} \geq 0 \sum_{t=1}^{T} f_{t}\left(x_{t+1}, y_{t}\right) \\
-\left(h_{t}\left(x_{t}\right)-g_{i t}\left(x_{t+1}, y_{t}\right)\right) g_{2}\left(x_{t+1}, y_{t}\right) \leq 0,
\end{gathered}
$$

where $L$ is the highest limit on $M\left(x_{1}\right)$. A subgradient method, a surrogate subgradient method, and a bundle method are used to solve the model $L$. The LR for $t=$ $1, \cdots, T$ is used to resolve the non-concavity problem, but this relaxed formulation overestimates any $t=$ $1, \cdots, T$. By focusing on the $(t+1) h$ stage problem, we can have a method closer to Future Revenue Functions (FRF).

$$
\begin{aligned}
& \left(M_{t}\right) \hat{\eta}_{t}\left(x_{1}\right):=\max _{x_{t+1}, y_{t} \geq 0} f_{t}\left(x_{t+1}, y_{t}\right)+\hat{\eta}_{t+1}, \\
& \text { s.t.: } \quad f_{t}\left(x_{t}\right)-g_{1},\left(x_{t+1}, y_{t}\right) \leq 0, \\
& \hat{\eta}_{t+1} \leq-\lambda_{l, t+1}, f_{t+1}\left(x_{t+1}\right)+\gamma_{l, t+1}^{\text {cons }}, \\
& \quad l=1, \cdots, L-1 .
\end{aligned}
$$

\subsection{Proposed combined BD-LR algorithm}

Using this composition, stronger bounds with higher effectiveness and lower iterations are captured to gain an optimal solution. Specifically, the obtained lower bound by LR is always better than the obtained lower bound by $\mathrm{BD}$; thus, convergence is guaranteed by the hybrid method. The Benders cut is optimally used along with the NBD. Herein, we have forward and backward passes. The objective of the forward pass region is to solve the original problem $(M)$ to obtain a lower bound on $M\left(x_{1}\right)$. In the backward pass, the aim is to generate valid Benders optimality cuts using trial $x_{t+1}$. By $\hat{L}_{1}\left(x_{1}\right)-M\left(x_{1}\right) \geq 0$, there is a gap between the lower bound $Z$ and the upper bound $z^{-}$, which do not converge. Through the combined BD and LR, the solution to $M$ and $M\left(x_{1}\right)$ is found. We can obtain the bounds by computing the optimality cuts on a relaxed problem. If the problem has a gap, as represented by $\hat{L}_{1}\left(x_{1}\right)-M\left(x_{1}\right) \geq 0, M$ and the combined $\mathrm{BD}$ and LR cannot solve $L$. At stage $t$, the computed cut is tight for $L_{T}\left(M_{T}\right)$; however, after multiple backward and forward passes, the computed cuts in $h_{t}\left(x_{t}\right)-g_{1_{t}}\left(x_{t+1}, y_{t}\right) \leq 0$ will be tight for all other stages. The steps of the proposed combined BD-LR algorithm are summarized in Figure 2. The definition of each step can be seen in Algorithm 1. 


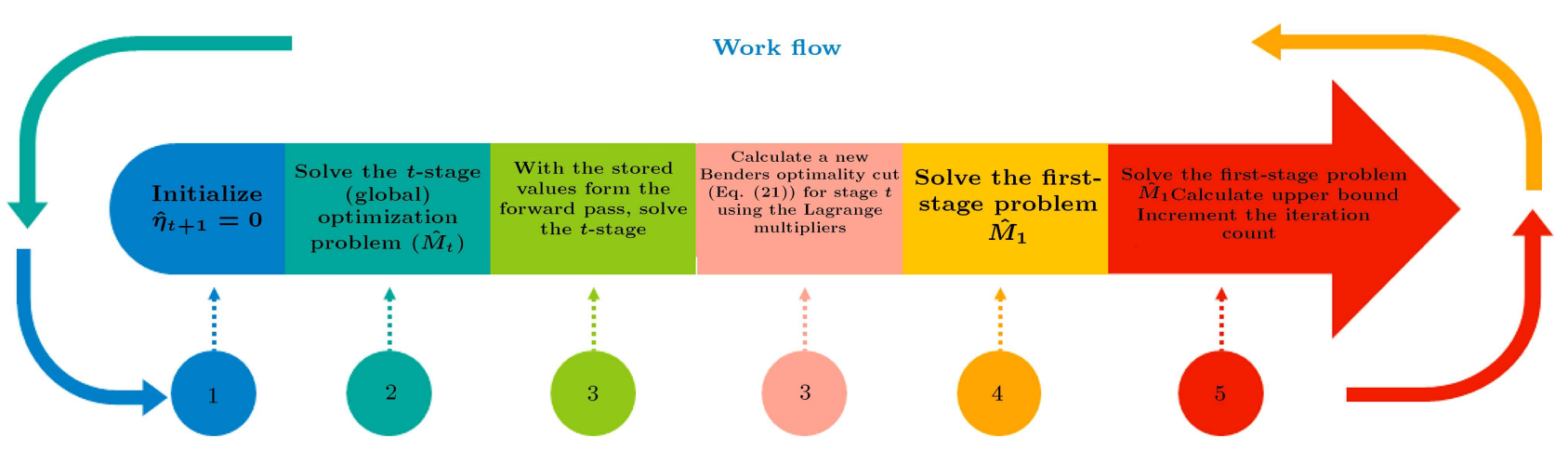

Figure 2. The work process of BD-LR.

\section{The combined BD-LR Algorithm}

1. Step (0): Initialize $\hat{\eta}_{\mathrm{t}+1}=0$

2. While Stopping criteria not satisfied do

3. Forward Pass

4. $\quad$ For $\mathrm{t}=1, \ldots, \mathrm{T}$ do

5. $\quad$ Step (1): Solve the $t$-stage (global) optimization problem $\left(\hat{\mathrm{M}}_{\mathrm{t}}\right)$

6. end for

7. Step (2): Update lower bound

8. Backward Pass

9. $\quad$ For $\mathrm{t}=\mathrm{T}, \mathrm{T}-1, \ldots, 2$ do

10. Step (3): With the stored $\lambda_{\mathrm{j}, \mathrm{t}}$ values from the forward pass, solve the $t$-stage

Lagrangian problem $\phi_{t}$ for (near) optimal Lagrangian multipliers.

11. Step (4): Calculate a new Benders optimality cut (Eq. 22) for stage $t$ using the

Lagrange multipliers and objective function value obtained from Step (3).

12. end for

13. Step (5): Solve the first-stage problem $\hat{\mathrm{M}}_{1}$

14. Step (6): Calculate upper bound

15. Step (7): Increase the iteration count

16. end while

17. Step (8): Exit

Algorithm 1. The combined BD-LR.

Based on the proposed model, two introduced objective functions are integrated first. Three categories of methods: 1) priori, 2) interactive, and 3) posteriori are at our disposal [43]. We employed posteriori method here, because this method, in comparison to the rest, provides a universal image from a Paretooptimal set for decision-makers. In doing so, they can choose the most preferred solution considering the available information. As a result, the integrated objective function is obtained by Eq. (25) as shown in Box I. as follows:

Then, the dual problem of function (Eq. (25)) is

$$
\begin{aligned}
\min F= & \sum_{i} \sum_{m} \sum_{s} \nu_{i m s}^{1} \cdot P_{i m}^{s}+\sum_{k} \sum_{m} \sum_{s} \nu_{k m s}^{2} \\
& \cdot C I D_{k}^{s}-\sum_{m} \sum_{s} \nu_{s m}^{3} \cdot D_{m}^{s}-\sum_{m} \sum_{s} \nu_{s m}^{4} \\
& \cdot D_{m}^{s}+\sum_{s} \sum_{k} \nu_{s k}^{5} \cdot M^{s} \cdot y_{k}^{s}-\sum_{s} \sum_{k} \nu_{s k}^{6}
\end{aligned}
$$




$$
\begin{aligned}
\widehat{M_{t} \max F_{1}=\frac{W_{1}}{S_{k}}}\left[\begin{array}{l}
\left.\sum_{k} \sum_{s} f_{k}^{s} \cdot y_{k}^{s}+\sum_{i} \sum_{s} D_{i}^{s} \cdot y_{i}^{s}+\sum_{i} \sum_{k} \sum_{m} \sum_{s} C_{i k m}^{s} \cdot x_{i k m}^{s}+\sum_{i} \sum_{j} \sum_{m} \sum_{s} C_{i j m}^{s} \cdot x_{i j m}^{s}\right] \\
+\sum_{k} \sum_{j} \sum_{m} \sum_{s} C_{k j m}^{s} \cdot x_{k j m}^{s}+\sum_{k} \sum_{m} \sum_{s} C_{k m}^{s} \cdot \operatorname{Re}_{k m}^{s}
\end{array}\right] \\
+\frac{W_{1}}{S_{k}^{\prime}}\left[\sum_{m} \sum_{s} \alpha^{s} \cdot D_{m}^{s}\left[\sum_{i} \sum_{j} \sum_{m} \sum_{s} L O S_{i j m}^{s} \cdot D_{m}^{s}\right]-\sum_{i} \sum_{j} \sum_{m} \sum_{s}\left(1-C_{i j m}^{s}\right) \cdot D_{m}^{s}\right],(25)
\end{aligned}
$$

Box I

$$
\begin{aligned}
& \cdot M^{s} \cdot y_{k}^{s}-\sum_{s} \nu_{s}^{8} \cdot B_{\min }+\sum_{s} \nu_{s}^{9} \cdot B_{\max } \\
& -\sum_{i} \sum_{j} \sum_{k} \sum_{\nu} y_{k j}\left(S_{i k}^{\nu} \cdot y_{i k}+S_{k j}^{\nu}+T_{k}^{\nu}\right) \nu_{\nu}^{11} \\
& +\sum_{k} \sum_{s} \nu_{k}^{12} \cdot C I D_{k}^{s} \\
& v_{i m s}^{1}-v_{s m}^{3}+v_{s k}^{5}+v_{s}^{7} \geq\left(w_{1} / S_{k}\right) \cdot \alpha^{s} L O S_{i j m} \\
& \forall i, j, m, s, k \\
& \left.v_{i m s}^{2}-v_{s m}^{4}+v_{s k}^{6}+v_{s}^{7} \geq\left(-w_{1} / S_{k}\right) \cdot \alpha^{s}\left(1-C A P_{i j m}^{s}\right)\right) \\
& \forall i, j, m, s, k \\
& v_{s k}^{5} \cdot M^{s}+v_{s k}^{6} \cdot M^{s}+v_{s}^{8}+v_{s}^{9} \geq\left(-w_{2} / S_{k}^{\prime}\right) \cdot f_{k}^{s} \\
& \forall s, k, \\
& v_{v c}^{10}-v_{v}^{11} \geq\left(-w_{2} / S_{k}^{\prime}\right) D C_{i}^{s} \quad \forall i, s, v \\
& -v_{v}^{10}-v_{v}^{11} \geq\left(-w_{2} / S_{k}^{\prime}\right) C_{i k m}^{s} \quad \forall i, m, s, k, \\
& v_{v}^{11} \geq\left(-w_{2} / S_{k}^{\prime}\right) C_{i j m}^{s} \quad \forall i, j, m, s, v, \\
& v_{v}^{11} \geq\left(-w_{2} / S_{k}^{\prime}\right) C_{k j m}^{s} \quad \forall k, j, m, s, v \\
& v_{k}^{12} \geq\left(-w_{2} / S_{k}^{\prime}\right) C_{k m}^{s} \quad \forall k, m, s, v \\
& \sum_{i=1}^{2} w_{i}=1 \\
& v_{i m s}^{1}, v_{i m s}^{2}, v_{s m}^{3}, v_{s m}^{4}, v_{s k}^{5}, v_{s k}^{6}, v_{s}^{8}, v_{s}^{9}, v_{v}^{11}, v_{k}^{12} \geq 0 \\
& \forall i, m, s, k, v \\
& v_{v}^{10}, v_{s}^{7} \quad \text { free } \forall s .
\end{aligned}
$$

Eq. (26) is the objective function of dual problem and $\nu$ with any indices presents the dual parameter. Constrains (27) to (36) are dual problem constraints as well. For the next step, the more complicated constraint(s) has to be added to Objective functions (Eqs. (37) and (38) as shown in Box II). The parameter $\lambda_{j, t+1}$ is the dual variable associated with delivery point $j$ at stage $t$. Furthermore, $\underline{V} \leq V_{t} \leq \bar{V}$ is the service level variable. Function $\hat{\beta}_{t+2}\left(V_{t+2}\right)$ is the approximate cumulative cost within stage $(t+2 \cdots T)$, while $\hat{\beta}_{t+1}(0)$ is approximated for every fixed value of $\lambda_{t+1}$ and $V_{t+1}$ through the linear cut:

$$
\sum \gamma_{j, t}^{\text {slope }} V_{j, t+1}+\gamma_{t}^{\text {const }}
$$

while:

$$
\begin{aligned}
& \gamma_{j, t}^{\text {slope }}=\lambda_{j, t+1} \\
& \gamma_{t}^{\text {const }}=\hat{\phi}_{t+1}\left(\lambda_{t+1}, V_{t+1}\right)-\sum_{j} \lambda_{j, t+1} V_{j, t+1}
\end{aligned}
$$

Solving the integrated objective function by the hybrid of BD and LR creates better results for decision variables in a shorter solving time. Shortening of the solving time takes place because of earlier convergence that LR brings about for BD.

\section{Case study}

We have considered a big E-commerce startup and online store to use its data as a case study. It offers a broad range of items (e.g., digital items, household devices, personal items, culture and art, sports, entertainment, etc.) from a large number of brands and possesses the largest share of online sales market of the country. The users and customers have a wide range of choices and receive extensive information regarding their required items enabling them to select proper items. The customers browse among items on the company's website/apps, select their intended 


$\widehat{M}_{1} \varphi_{t+1}\left(\lambda_{t+1}, V_{t+1}\right)=\min \left[\begin{array}{c}\sum_{i} \sum_{m} \sum_{s} \nu_{i m s}^{1} \cdot P_{i m}^{s}+\sum_{k} \sum_{m} \sum_{s} \nu_{k m s}^{2} \cdot C I D_{k}^{s}-\sum_{m} \sum_{s} \nu_{s m}^{3} \cdot D_{m}^{s} \\ -\sum_{m} \sum_{s} \nu_{s m}^{4} \cdot D_{m}^{s}+\sum_{s} \sum_{k} \nu_{s k}^{5} \cdot M^{s} \cdot y_{k}^{s}-\sum_{s} \sum_{k} \nu_{s k}^{6} \cdot M^{s} \cdot y_{k}^{s} \\ -\sum_{s} \nu_{s}^{8} \cdot B_{\min }+\sum_{s} \nu_{s}^{9} \cdot B_{\max } \\ -\sum_{i} \sum_{j} \sum_{k} \sum_{\nu} y_{k j}\left(S_{i k}^{\nu} \cdot y_{i k}+S_{k j}^{\nu} \cdot y_{k j}+T_{k}^{\nu}\right) \nu_{\nu}^{11} \\ +\sum_{k} \sum_{s} \nu_{k}^{12} \cdot C I D_{k}^{s} \sum_{j} \lambda_{j, t+1} \cdot \frac{W_{1}}{S_{k}} \\ \cdot \alpha^{t+1}\left(L O S_{j, t+1}-\left(1-C a P_{j}^{t+1}\right)-\widehat{\beta}_{t+2}\left(V_{t+2}\right) \nu_{k}^{12}\right)\end{array}\right]$

Box II

items, and then proceed with their ordering and purchasing process.

Company's distribution system includes direct sales of an item through online sales system and delivery of the items to customer's address, delivery to intermediary depots or close-to-buyer distribution centers, buying an item from predetermined purchase centers within the distribution network, and buying an item from intermediary depots and delivery to the customer's location. Our case has a central distribution system, two intermediary depots located in different cities, and diverse delivery points. Hence, we face a seller and distributer company with different ways to deliver its products to the customer. Eight ways that a seller can take are described in Section 4 .

Taking into account the relevant scenario described in the problem statement, the shipping capacity of intermediary depots is 20000 and 5000 units per day. In the case of the main distribution center, the capacity is 100000 units per day. Total demand for three types of items including cellphone, computer accessories, and laptops is 4500,15000 , and 3000 units, respectively. In addition, the fixed cost of establishing the intermediary depots 1 and 2 is 15.000 and 18.000 monetary units, respectively. Moreover, holding cost in these depot points is 25 and 23 units per item, respectively. Based on the decisions made by senior managers of the company, the minimum number of intermediary depots established based on different scenarios is assumed zero, but the maximum capacity for both of the intermediary depots is used. Also, each scenario rate is based on the existence of situations and qualifications the manufacturer/distributor can present. It is estimated by the manufacturer/distributor knowing their capacity and the potential set of their properties and features.

Drawing on the above data, the proposed combined BD-LR method was implemented using a PC with a $3.4 \mathrm{GHz}$ Intel CoreTM i7-2600 processor and 4 GM RAM memory in GAMS 24 to find the optimal solution to the mathematical model developed in this paper. To do so, five scenarios based on different service levels including $0.77,0.83,0.87,0.91$, and 0.95 were taken into account. Table 1 gives the obtained results for the proposed model.

Table 1. Objective function values based on different scenarios.

\begin{tabular}{cccccc}
\hline Scenario & $\begin{array}{c}\text { Intermediary } \\
\text { depot }\end{array}$ & $\begin{array}{c}\text { The capacity of } \\
\text { intermediary depot }\end{array}$ & $\begin{array}{c}\text { The number of } \\
\text { rejected items }\end{array}$ & Satisfaction & Cost \\
\hline 1 & 1,2 & 100,000 & 412 & 0.77 & 14395 \\
2 & $1,2,3$ & 140,000 & 675 & 0.83 & 14609 \\
3 & $1,2,3,4$ & 160,000 & 933 & 0.87 & 15370 \\
4 & 1 & 70,000 & 218 & 0.91 & 15165 \\
5 & 1,3 & 110,000 & 412 & 0.95 & 14485 \\
\hline
\end{tabular}


Table 1 shows the obtained results for each of the two objective functions in each of the five scenarios. In the case of the second objective function, higher service level is correlated with higher customer satisfaction. On the other hand, in the case of the first objective function, higher service level is associated with the lower system cost. This is because of equality of demand and supply, which results in lower inventory in depots and, thus, lower cost of holding inventory. We considered lower and upper bound for "intermediary depot", "the capacity of intermediary depot", and "the number of rejected items" based on possibilities. Then, experts' ideas recognized appropriate numbers for these parameters considering existing possibilities. Hence:

- In Scenario 1, intermediary numbers 1 and 2 with the capacity of 100,000 would be open. If the number of rejected items is 412 , satisfaction is 0.77 and cost is 14395 ;

- In Scenario 2, in addition to intermediary numbers 1 and 2, the intermediary number 3 opens which results in higher cost along with a new opportunity brought about by a greater space, which means 140,000 items. The number of rejected items is 675 , which is larger than that in the previous scenario. However, in comparison to the increased capacity, the difference between this scenario and the previous one is not significant. This additional intermediary causes higher cost, while this increase in capacity means increasing the speed of delivery to customers, leading to satisfaction increase to 0.83 ;

- In Scenario 3, the fourth intermediary depot opened, which raised the cost to 15370 . The capacity increased to 160,000 with 933 rejected items. In fact, the rate of rejection in terms of maximum items in intermediary depot (which means the higher rate of delivery products) has faced a greater difference, compared to Scenarios 1 and 2. Hence, satisfaction got +3 points and reached 0.87 (in comparison to the previous scenario with +6 point increase);

- In Scenario 4, we just have an intermediary depot with the capacity of 70,000 items. While the number of items delivered is reduced, the number of rejections is reduced as well. However, the number of rejections in comparison to capacity (maximum number of items stocked and, then, delivered in each period) is lower than Scenarios 1 to 3 , pointing to higher satisfaction;

- In Scenario 5, intermediary numbers 1 and 3 were opened with the total capacity of 110,000 and the rejection rate near to Scenario 4 and lower than the rest of them. This lower rejection implies higher satisfaction which, along with reasonable costs, makes the most productive scenario.

In general, in the case of moving from the first to the third scenario (i.e., increasing the service level from 0.77 to 0.87 ), the cost of the system increases from 14395 to 15370 units, showing an incremental trend. However, the cost decreases by moving from the fourth to fifth scenario (i.e., increasing the service level from 0.91 to 0.95 ). The reason behind the latter case is the fact that where the service level gets closer to $100 \%$, the holding cost tends toward zero so that the cost components in parts 1 and 3 of the first objective function will be zero. This is because higher satisfaction can generate higher demand, which, in turn, means lower inventory and lower holding cost. Higher satisfaction can be a result of lower prices due to lower costs of production process, lower delays, and lower missed order. The cost component in the second objective function that shows shipping costs of the whole system also follows the same logic.

Table 2 displays the comparison between the results achieved from our model and the model of Abdulkader et al. [21]. They developed a two-phase heuristic and multi-ant colony algorithm to solve the mathematical model formulated for an omni-channel distribution system that decides on allocating consumers to stores and finding vehicle routes based on inventory availability to reduce total traveling costs. Also, Table 3 shows the number of decision variables

Table 2. Comparison of objective function values.

\begin{tabular}{|c|c|c|c|c|c|c|c|}
\hline \multirow[b]{3}{*}{ Scenario } & \multicolumn{6}{|c|}{ Proposed model } & \multirow{3}{*}{$\begin{array}{c}\text { Model proposed by } \\
\text { Abdulkader et al. }[21 \\
\text { Objective function } \\
\text { Optimum } \\
\text { amount }\end{array}$} \\
\hline & \multicolumn{3}{|c|}{ Objective function (1) (\%) } & \multicolumn{3}{|c|}{ Objective function (2) (\%) } & \\
\hline & $\begin{array}{l}\text { Upper } \\
\text { bound }\end{array}$ & $\begin{array}{c}\text { Optimum } \\
\text { amount }\end{array}$ & $\begin{array}{l}\text { Lower } \\
\text { bound }\end{array}$ & $\begin{array}{l}\text { Upper } \\
\text { bound }\end{array}$ & $\begin{array}{c}\text { Optimum } \\
\text { amount }\end{array}$ & $\begin{array}{l}\text { Lower } \\
\text { bound }\end{array}$ & \\
\hline 1 & 13965 & 14395 & 15355 & 0.82 & 0.77 & 0.66 & 16400 \\
\hline 2 & 14015 & 14609 & 15545 & 0.87 & 0.83 & 0.74 & 18790 \\
\hline 3 & 14300 & 15370 & 16785 & 0.89 & 0.87 & 0.73 & 19700 \\
\hline 4 & 15750 & 15165 & 16540 & 0.93 & 0.91 & 0.87 & 16000 \\
\hline 5 & 14175 & 14485 & 15395 & 0.98 & 0.95 & 0.90 & 15800 \\
\hline
\end{tabular}


Table 3. Amounts of decision variables in different scenarios.

\begin{tabular}{|c|c|c|c|c|c|c|c|}
\hline Scenarios & $\begin{array}{c}\text { Distributable } \\
\text { items }\end{array}$ & $\begin{array}{c}\text { Distribution } \\
\text { centers }\end{array}$ & $\begin{array}{c}\text { Delivery } \\
\text { points }\end{array}$ & $\begin{array}{c}\text { Intermediary } \\
\text { depots }\end{array}$ & $\boldsymbol{x}_{i j m}^{s}$ & $x_{k j m}^{s}$ & $\boldsymbol{x}_{i k m}^{s}$ \\
\hline \multirow{9}{*}{1} & \multirow{3}{*}{1} & 1 & 1 & 1 & 73 & 92 & 87 \\
\hline & & 2 & 2 & 2 & 85 & 93 & 87 \\
\hline & & 3 & 3 & 3 & 83 & 91 & 87 \\
\hline & \multirow{3}{*}{2} & 1 & 1 & 1 & 83 & 91 & 88 \\
\hline & & 2 & 2 & 2 & 87 & 92 & 89 \\
\hline & & 3 & 3 & 3 & 87 & 89 & 90 \\
\hline & \multirow{3}{*}{3} & 1 & 1 & 1 & 78 & 91 & 89 \\
\hline & & 2 & 2 & 2 & 89 & 92 & 75 \\
\hline & & 3 & 3 & 3 & 90 & 88 & 75 \\
\hline \multirow{9}{*}{2} & \multirow{4}{*}{1} & 1 & 1 & 1 & 84 & 87 & 73 \\
\hline & & 2 & 2 & 2 & 85 & 89 & 85 \\
\hline & & 3 & 3 & 3 & 84 & 91 & 83 \\
\hline & & 1 & 1 & 1 & 85 & 87 & 87 \\
\hline & \multirow[t]{2}{*}{2} & 2 & 2 & 2 & 86 & 86 & 80 \\
\hline & & 3 & 3 & 3 & 87 & 85 & 85 \\
\hline & \multirow{3}{*}{3} & 1 & 1 & 1 & 87 & 89 & 89 \\
\hline & & 2 & 2 & 2 & 89 & 92 & 85 \\
\hline & & 3 & 3 & 3 & 92 & 91 & 84 \\
\hline \multirow{9}{*}{3} & \multirow{3}{*}{1} & 1 & 1 & 1 & 86 & 92 & 90 \\
\hline & & 2 & 2 & 2 & 92 & 89 & 87 \\
\hline & & 3 & 3 & 3 & 87 & 87 & 91 \\
\hline & \multirow{3}{*}{2} & 1 & 1 & 1 & 87 & 89 & 91 \\
\hline & & 2 & 2 & 2 & 87 & 87 & 87 \\
\hline & & 3 & 3 & 3 & 88 & 88 & 87 \\
\hline & \multirow{3}{*}{3} & 1 & 1 & 1 & 89 & 90 & 87 \\
\hline & & 2 & 2 & 2 & 90 & 87 & 87 \\
\hline & & 3 & 3 & 3 & 89 & 87 & 88 \\
\hline \multirow{9}{*}{4} & \multirow{3}{*}{1} & 1 & 1 & 1 & 75 & 93 & 89 \\
\hline & & 2 & 2 & 2 & 75 & 94 & 90 \\
\hline & & 3 & 3 & 3 & 73 & 92 & 89 \\
\hline & \multirow{3}{*}{2} & 1 & 1 & 1 & 85 & 93 & 75 \\
\hline & & 2 & 2 & 2 & 83 & 91 & 75 \\
\hline & & 3 & 3 & 3 & 87 & 92 & 73 \\
\hline & \multirow{3}{*}{3} & 1 & 1 & 1 & 80 & 91 & 85 \\
\hline & & 2 & 2 & 2 & 85 & 90 & 83 \\
\hline & & 3 & 3 & 3 & 89 & 89 & 87 \\
\hline \multirow{9}{*}{5} & \multirow{3}{*}{1} & 1 & 1 & 1 & 85 & 90 & 80 \\
\hline & & 2 & 2 & 2 & 84 & 89 & 85 \\
\hline & & 3 & 3 & 3 & 90 & 87 & 89 \\
\hline & \multirow{3}{*}{2} & 1 & 1 & 1 & 87 & 90 & 85 \\
\hline & & 2 & 2 & 2 & 91 & 88 & 84 \\
\hline & & 3 & 3 & 3 & 91 & 89 & 90 \\
\hline & \multirow{3}{*}{3} & 1 & 1 & 1 & 87 & 90 & 87 \\
\hline & & 2 & 2 & 2 & 87 & 92 & 91 \\
\hline & & 3 & 3 & 3 & 88 & 93 & 91 \\
\hline
\end{tabular}




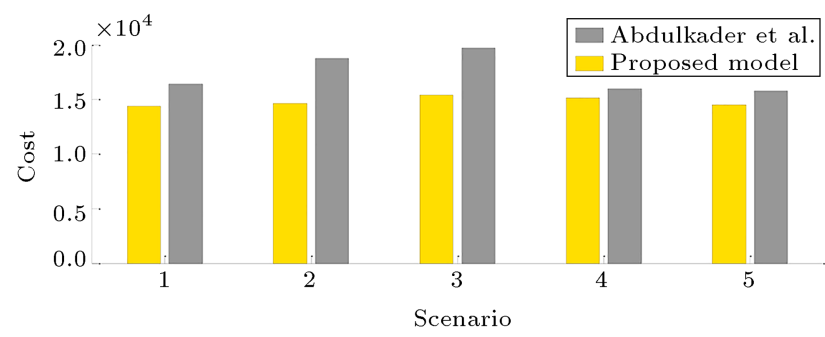

Figure 3. Comparative results for the objective function (Eq. (1)) (cost).

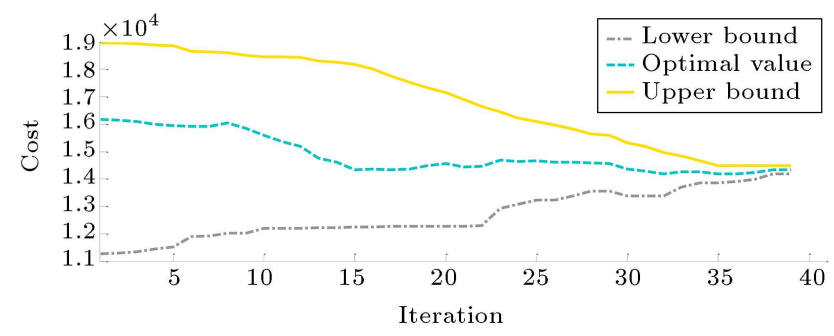

Figure 4. Convergence of objective function.

and items shipped among points considering different scenarios.

Results of the model proposed by Abdulkader et al. [21] follow the same trend, but with higher costs. The values of the first objective functions (i.e., cost components) for the same scenario are higher in the model proposed by Abdulkader et al. [21]. Figure 3 illustrates comparative results for the objective function (Eq. (1)).

As shown in Figure 3, the proposed model generates a lower holding cost than that of Abdulkader et al. [21] for all of the investigated scenarios. The convergence of the objective function in our model is shown in Figure 4. Considering this figure for upper and lower bounds and optimal values, after 39 iterations, the convergence occurred. Also, the values of all lines are close to each other. The speed of this convergence is also reasonable.

\section{Conclusion}

The fierce competition in the retailing market forced retailers to develop diverse distribution channels to deliver items based on requirements of customers. Previously, supply chains were based on traditional sales methods where the producer shipped the items to the retailers that sold the items to the customers at higher prices. In recent years, technological developments created significant opportunities for companies to multiply their profit by opting for enhanced distribution policies and direct sale of items, which exclude intermediaries from the sales process. The companies could now sell their products directly to consumers through online channels. The omni-channel distribution emerged following the development of dif- ferent distribution methods in supply chains and using enhanced communication technologies. It is currently regarded as a promising distribution approach since it takes advantage of all communication ways and maximizes the efficiency of distribution of items.

In this paper, a multi-objective mathematical modeling approach was presented to optimize the flow of items in an omni-channel distribution context under uncertainty. The objective was minimization of supply chain costs consisting of establishing distribution centers, establishing intermediate depots, transportation and rejected items while maximizing customer satisfaction in comparison with Abdulkader et al. [21] with only one objective function for minimizing transportation cost. In addition, we proposed a combined BD-LR algorithm to solve the mathematical model. The model was then implemented in the company's distribution network based on five different probable scenarios with different and available service levels (i.e., 0.77, 0.83, $0.87,0.91$, and 0.95). Indeed, these scenarios were considered based on probable situation, compositions the company had, and service levels introduced based on the real service level the company could prepare. The results demonstrated that higher service levels were followed by higher customer satisfaction. In particular, the first objective function demonstrated that higher service levels were correlated with lower costs of the system in a way that if service level got closer to $100 \%$, holding costs would tend to zero. Furthermore, the results of comparing the proposed model with those obtained from the model presented by Abdulkader et al. [21] demonstrated that all objective functions were enhanced over all the scenarios.

The advance of the Internet and new technologies over the last decade has transformed the retailing panorama. More and more channels are emerging, causing consumers to change their habits and shopping behavior. An omnichannel strategy is a form of retailing that, by enabling real interaction, allows customers to shop across channels anywhere and at any time, thereby providing them with a unique, complete, and seamless shopping experience that breaks down the barriers between channels. The expansion of the Internet has dramatically threatened businesses' ability to retain their customers. Given that customer retention affects growth and profitability, effective customer retention strategies in the omni-channel distribution systems are essential to businesses. From a managerial perspective, it is very difficult to influence and control e-trust directly, as e-trust is the result of multilateral interactions with omni-channel service providers, brand effects, and service-specific features such as technology convenience. However, in an omni-channel sales environment, reliability is a dimension of service quality that can be controlled directly and exclusively by the service provider. According to what was mentioned, 
price and delivery time represented the factors that determine customer satisfaction when evaluating a product. Raising the level of customer satisfaction to the same extent as increasing product sales and enhancing the profitability of the organization can also lead to the opposite result. Increased satisfaction affects all aspects of the organization. Accordingly, this study showed that in order to reduce costs and increase customer satisfaction, different ways of delivering goods and services from distributor to customer had to be designed in order to be able to retain customers. All of this can be achieved through the design of a omnichannel strategy. Some other lines of research can employ other optimization algorithms and compare them in order to find an appropriate algorithm. Other objective functions like the one minimizing waste can be considered in future studies as well, taking into consideration other objective functions that should be employed.

\section{References}

1. Jolai, F., Razmi, J., and Rostami, N.K.M. "A fuzzy goal programming and meta heuristic algorithms for solving integrated production: distribution planning problem", Cent. Eur. J. Oper. Res., 19(4), pp. 547569 (2011).

2. Hendalianpour, A., Fakhrabadi, M., Zhang, X., Feylizadeh, M.R., Gheisari, M., Liu, P., and Ashktorab, N. "Hybrid model of IVFRN-BWM and robust goal programming in agile and flexible supply chain, a case study: Automobile industry", IEEE Access, 7, pp. 71481-71492 (2019).

3. Hendalianpour, A. and Razmi, J. "Customer satisfaction measurement using fuzzy neural network", Decis. Sci. Lett., 6(2), pp. 193-206 ( 2017).

4. Hendalianpour, A., Razmi, J., Fakhrabadi, M., Kokkinos, K., and Papageorgiou, E.I. "A linguistic multiobjective mixed integer programming model for multiechelon supply chain network at bio-refinery", EuroMed J. Manag., 2(4), pp. 329-355 (2018).

5. Amirtaheri, O., Zandieh, M., and Dorri, B. "A bi-level programming model for decentralized manufacturerdistributer supply chain considering cooperative advertising", Scientia Iranica, 25(2), pp. 891-910 (2018).

6. Chan, F.T.S. and Kumar, N. "Effective allocation of customers to distribution centres: A multiple ant colony optimization approach", Robot. Comput. Integr. Manuf., 25(1), pp. 1-12 (2009).

7. Jocevski, M., Arvidsson, N., Miragliotta, G., Ghezzi, A., and Mangiaracina, R. "Transitions towards omnichannel retailing strategies: a business model perspective", Int. J. Retail Distrib. Manag., 47(2), pp. 78-93 (2019).

8. Fikar, C. "A decision support system to investigate food losses in e-grocery deliveries", Comput. Ind. Eng., 117, pp. 282-290 (2018).
9. Song, G., Song, S., and Sun, L. "Supply chain integration in omni-channel retailing: a logistics perspective", Int. J. Logist. Manag., 30(2), pp. 527-548 (2019).

10. Pereira, M.M. and Frazzon, E.M. "Towards a predictive approach for omni-channel retailing supply chains", IFAC-Papers OnLine, 52(13), pp. 844-850 (2019).

11. Sohn, S. "Consumer processing of mobile online stores: Sources and effects of processing fluency", J. Retail. Consum. Serv., 36, pp. 137-147 (2017).

12. Oghazi, P., Karlsson, S., Hellström, D., and Hjort, K. "Online purchase return policy leniency and purchase decision: Mediating role of consumer trust", J. Retail. Consum. Serv., 41, pp. 190-200 (2018).

13. Sharma, M., Gupta, M., and Joshi, S. "Adoption barriers in engaging young consumers in the omnichannel retailing", Young Consumers Insight and Ideas for Responsible Marketers, 21(2), pp. 193-210 (2019). doi.org/10.1108/YC-02-2019-0953

14. Tabrizi, B.H. and Razmi, J. "A robust optimisation model for global distribution networks design", Int. J. Logist. Syst. Manag., 16(1), pp. 85-97 (2013).

15. Tian, L., Ge, Y., and Xu, Y. "A stochastic multi-channel revenue management model with timedependent demand", Comput. Ind. Eng., 126, pp. 465471 (2018).

16. Cintron, A., Ravindran, A.R., and Ventura, J.A. "Multi-criteria mathematical model for designing the distribution network of a consumer goods company", Comput. Ind. Eng., 58(4), pp. 584-593 (2010).

17. Kembro, J.H. and Norrman, A. "Warehouse configuration in omni-channel retailing: a multiple case study", Int. J. Phys. Distrib. Logist. Manag., 50(5), pp. 509533 (2020).

18. Li, Y., Li, G., Tayi, G.K., and Cheng, T.C.E. "Omnichannel retailing: Do offline retailers benefit from online reviews?", Int. J. Prod. Econ., 218, pp. 43-61 (2019).

19. Wollenburg, J., Hübner, A., Kuhn, H., and Trautrims, A. "From bricks-and-mortar to bricks-and-clicks", Int. J. Phys. Distrib. Logist. Manag., 48(4), pp. 415-438 (2018).

20. Xu, X. and Jackson, J.E. "Investigating the influential factors of return channel loyalty in omni-channel retailing", Int. J. Prod. Econ., 216, pp. 118-132 (2019).

21. Abdulkader, M.M.S., Gajpal, Y., and ElMekkawy, T.Y. "Vehicle routing problem in omni-channel retailing distribution systems", Int. J. Prod. Econ., 196, pp. 43-55 (2018).

22. Yrjölä, M., Spence, M.T., and Saarijärvi, H. "Omnichannel retailing: propositions, examples and solutions", Int. Rev. Retail. Distrib. Consum. Res., 28(3), pp. 259-276 (2018).

23. Rosenmayer, A., McQuilken, L., Robertson, N., and Ogden, S. "Omni-channel service failures and recoveries: refined typologies using Facebook complaints", $J$. Serv. Mark., 32(3), pp. 269-285 (2018). 
24. Melacini, M. and Tappia, E. "A critical comparison of alternative distribution configurations in omni-channel retailing in terms of cost and greenhouse gas emissions", Sustainability, 10(2), p. 307 (2018).

25. Hosseini, S., Merz, M., Röglinger, M., and Wenninger, A. "Mindfully going omni-channel: An economic decision model for evaluating omni-channel strategies", Decis. Support Syst., 109, pp. 74-88 (2018).

26. Beck, N. and Rygl, D. "Categorization of multiple channel retailing in multi-, cross-, and omni-channel retailing for retailers and retailing", J. Retail. Consum. Serv., 27, pp. 170-178 (2015).

27. Verhoef, P.C., Kannan, P.K., and Inman, J.J. "From multi-channel retailing to omni-channel retailing", $J$. Retail., 91(2), pp. 174-181 (2015).

28. Sharma, M.J., Moon, I., and Bae, H. "Analytic hierarchy process to assess and optimize distribution network", Appl. Math. Comput., 202(1), pp. 256-265 (2008).

29. Li, C. and Liu, S. "Random network models and sensitivity algorithms for the analysis of ordering time and inventory state in multi-stage supply chains", Comput. Ind. Eng., 70, pp. 168-175 (2014).

30. Ashayeri, J., Ma, N., and Sotirov, R. "The redesign of a warranty distribution network with recovery processes", Transp. Res. Part E Logist. Transp. Rev., 77, pp. 184-197 (2015).

31. Pop, P.C., Pintea, C.-M., Pop Sitar, C., and HajduMăcelaru, M. "An efficient reverse distribution system for solving sustainable supply chain network design problem", J. Appl. Log., 13(2), pp. 105-113 (2015).

32. Ahmadi-Javid, A. and Hoseinpour, P. "A locationinventory-pricing model in a supply chain distribution network with price-sensitive demands and inventorycapacity constraints", Transp. Res. Part E Logist. Transp. Rev., 82, pp. 238-255 (2015).

33. Hübner, A., Holzapfel, A., and Kuhn, H. "Distribution systems in omni-channel retailing", Bus. Res., 9(2), pp. 255-296 (2016).

34. Huré, E., Picot-Coupey, K., and Ackermann, C.L. "Understanding omni-channel shopping value: A mixed-method study", J. Retail. Consum. Serv., 39, pp. $314-330$ (2017).

35. Kang, J.-Y.M. "What drives omnichannel shopping behaviors? Fashion lifestyle of social-localmobile consumers", Journal of Fashion Marketing and Management, 23(2), pp. 224-238 (2019). https://doi.org/10.1108/JFMM-07-2018-0088

36. Ryu, M.H., Cho, Y., and Lee, D. "Should smallscale online retailers diversify distribution channels into offline channels? Focused on the clothing and fashion industry", J. Retail. Consum. Serv., 47, pp. 74-77 (2019).

37. Saghiri, S., Wilding, R., Mena, C., and Bourlakis, M. "Toward a three-dimensional framework for omnichannel", J. Bus. Res., 77, pp. 53-67 (2017).
38. Song, S., Shi, X., and Song, G. "Supply chain integration in omni-channel retailing: a human resource management perspective", Int. J. Phys. Distrib. \& Logist. Manag., 50(1), pp. 101-121 (2019).

39. Wang, Q., McCalley, J.D., Zheng, T., and Litvinov, E. "Solving corrective risk-based security-constrained optimal power flow with Lagrangian relaxation and Benders decomposition", Int. J. Electr. Power Energy Syst., 75, pp. 255-264 (2016).

40. Steeger, G. and Rebennack, S. "Dynamic convexification within nested Benders decomposition using Lagrangian relaxation: An application to the strategic bidding problem", Eur. J. Oper. Res., 257(2), pp. 669686 (2017).

41. Rebennack, S. "Combining sampling-based and scenario-based nested Benders decomposition methods: application to stochastic dual dynamic programming", Math. Program., 156(1-2), pp. 343-389 (2016).

42. Rahmaniani, R., Crainic, T.G., Gendreau, M., and Rei, W. "The Benders decomposition algorithm: A literature review", Eur. J. Oper. Res., 259(3), pp. 801817 (2017).

43. Pishvaee, M.S., Razmi, J., and Torabi, S.A. "An accelerated Benders decomposition algorithm for sustainable supply chain network design under uncertainty: A case study of medical needle and syringe supply chain", Transp. Res. Part E Logist. Transp. Rev., 67, pp. 1438 (2014).

\section{Biographies}

Ayad Hendalianpour accomplished his BSc in Industrial Engineering at Islamic Azad University of Shiraz, Shiraz, Iran in 2009 and MSc in Industrial Engineering at Tehran University in 2014. His main research focuses on the digitalization of supply chain, logistics, and transportation (specifically using mathematical modelling) in a competitive environment. Moreover, he has studied different areas of industrial engineering like machine learning, operations research, feasibility study, and advanced analytics for more than seven years. He has presented over ten supply chain and logistics workshops for different companies. In addition, he has consulted different companies in recent years and solved their industrial engineering issues through consultation, training, and planning.

Mahnaz Fakhrabadi accomplished his BSc in Mathematics at Payam Nor University of Shiraz, Shiraz, Iran in 2005 and MSc in Industrial Engineering at the Department of Industrial Engineering, Amirkabir University of Technology (Tehran Polytechnic), Tehran, Iran. Now, she is a PhD research scholar at the Department of Business and Management Science at University of NHH Norwegian School of Economics, Bergen, Norway. She has worked on risk management, operations research, green and sustainable supply chain, logistic, 
and distribution networks. She is currently studying optimal control in energy section. She is also a reviewer of Cleaner Production Journal.

Mohamad Sadegh Sangari received his $\mathrm{PhD}$ from University of Tehran, Iran. His research interests include Supply Chain and Operations Management (SCM/OM), Information Technology/Systems (IT/IS) management, and customer relationship with a specific focus on application of advanced modeling and data analysis approaches, including Multivariate Data Analysis (MVDA) methods as well as optimization and decision analysis. He has published more than 30 papers in peer-reviewed journals and international conferences. He also teaches courses in industrial engineering and MBA and serves as a reviewer for several international journals.

Jafar Razmi is a Professor at the School of Industrial Engineering at the University of Tehran, Tehran, Iran. He teaches undergraduate and graduate courses in industrial engineering, operations management, and MS. He has published over 70 papers in peer-reviewed journals and published more than 70 papers in international conferences. He is a member in the editorial board of several academic journals. His research interests include supply chain management, operations management, production planning and control, lean manufacturing, and manufacturing measurement and evaluation. 